\title{
PREFERENSI KONSUMEN IKAN LAUT SEGAR BENGKULU ATAS BRAND EQUITY SEBAGAI JAMINAN KUALITAS PRODUK
}

\section{Consumer Preference of Bengkulu Fresh Sea Fish of Brand Equity as Guarantee of Product Quality}

\author{
Bonodikun, Putri Suci Asriani, dan Budiyanto \\ Fakultas Pertanian Universitas Bengkulu \\ E-mail:bonodikuns@yahoo.co.id
}

\begin{abstract}
Fisheries products in Bengkulu Province are still not to be classified well, so it may be considered not necessary to develop the discourse of product quality assurance. Regardless, the demands of globalization require each manufacturer to think ahead about the quality of the product "deserves" to be marketed, both in terms of the beneficial, characteristic, and image. Consumers have ample opportunity to get a product that is "inappropriate" according to his preference, one of which is through the use of brand equity as a guarantee of product quality as measured by the consumer response to price and product. The purposes of this study are: (1) to explain the relationship between the beneficial variables, characteristic, and the image of the brand equity variables, and (2) to analyze consumer response to the presence of the brand. From the results of this study also noted that the level of consumer preferences towards brand used by trader fresh fish is high in the city of Bengkulu. Assessment is based on expediency consumer brand presence (beneficial), the specific features that exist on the brand/merchant customer fresh sea fish (characteristic), and the picture attached to the brand (image). Based on the results of the Pearson test is known that the beneficial variables and the use of brand image on fresh fish merchant in the city of Bengkulu has a positive relationship to brand equity inherent in the product. Furthermore, it's also obtained information that the consumer response to the presence of a brand that is used by trader fresh fish in the city of Bengkulu as a guarantee of quality is very good.
\end{abstract}

Keywords: consumer preferences, marine fish, brand equity, quality assurance

\section{PENDAHULUAN}

Usaha komersialisasi dan pelepasan produk-produk hasil usaha perikanan tangkap mendapat tanggapan yang berbeda-beda di berbagai negara tujuan ekspor dan konsumen domestiknya. Tanggapan tersebut dapat digolongkan menjadi mempercepat (promotional), netral (permissive), memperlambat (precautionary), dan menolak (preventive), dengan pertimbangan 
atau alasan yang dikemukakan menyangkut hak atas kekayaan intelektual, biosafety dan lingkungan, serta perdagangan dan keamanan pangan. Sehubungan dengan isu keamanan pangan ini, maka diperlukan brand equity dalam produk perikanan tangkap yang dipasarkan (Huseini, 2007).

Bengkulu merupakan salah satu provinsi di Indonesia yang terdata memiliki potensi perikanan tangkap yang cukup signifikan untuk dikembangkan dengan potensi lestari sebesar 126.089 ton/tahun. Tingkat pengelolaan sumberdaya kelautan di provinsi ini baru mencapai sekitar 21,3\% dan beberapa ikan yang memiliki nilai ekonomi serta populasi yang sangat tinggi belum termanfaatkan secara baik. Hal ini selain disebabkan oleh terbatasnya pengetahuan dan teknologi yang dimiliki untuk mengeksploitasi sumberdaya perikanan tangkap tersebut, juga disebabkan oleh rendahnya diversifikasi produk, rendahnya penguasaan pasar, dan terjadinya distorsi pasar. Jaminan atas kualitas produk yang dapat dinikmati konsumen merupakan salah satu faktor penting yang harus diperhatikan sebelum kemudian mulai menetapkan rencana pengembangan usaha di sektor hilir.

Untuk mengoptimalkan potensi usaha perikanan tangkap Bengkulu, maka perlu diketahui informasi yang berkaitan dengan preferensi konsumen. Diketahui bahwa setiap wilayah pasar memiliki spesifikasi konsumen yang berbeda-beda. Dalam penelitian Anderson (1982) disampaikan bahwa untuk menetapkan kebutuhan konsumen atas jaminan kualitas (brand equity) suatu produk dengan konsekuensi harga (sebagai pendekatan TCE) perlu dilakukan penelitian yang didasarkan pada teori pemasaran dan TCE. Selain itu menurut Peter, et al. (2000), konsumen dapat menentukan pilihan produk yang diinginkannya sesuai dengan kebutuhan atas atribut produk, manfaat yang dapat dinikmati, nilai produk, budaya dan kebiasaan, serta kepribadiannya. Maka selanjutnya guna menjembatani informasi-informasi tersebut akan dilakukan penelitian tentang brand equity di sektor perikanan tangkap Bengkulu sebagai sebuah pendekatan biaya transaksi ekonomi.

Merujuk pada pentingnya pengembangan pasar produk ikan laut segar melalui jaminan kualitas yang tercermin pada brand yang melekat (Koswara, 2006), maka salah satu caranya adalah melalui pengujian preferensi konsumen ikan laut segar Bengkulu terhadap brand equity sebagai jaminan kualitas produk. Oleh karena itu, permasalahan pada penelitian ini adalah (1) menentukan faktor-faktor apa saja yang berhubungan dengan brand equity produk ikan laut segar Bengkulu; dan (2) menganalisis respon konsumen atas produk ikan laut segar dengan harga dan produk sebagai konsekuensi brand. 


\section{METODE PENELITIAN}

Penelitian ini dilaksanakan dengan pendekatan studi kasus, berdasarkan model Eisenhardt (1989) dalam Barcala, et al (2006). Model penelitian studi kasus ini merupakan pendekatan penelitian yang valid dan alat yang sesuai, terutama ketika tidak/sulit mendapatkan pemahaman yang lengkap atas suatu permasalahan (Coase, 1972; Eisenhardt, 1989; Yin, 2003 dalam Barcala, et al. 2006). Hal ini terjadi ketika dalam penelitian ini sulit untuk menjelaskan faktor-faktor yang mempengaruhi brand equity di sektor perikanan tangkap Bengkulu. Selain itu, pendapat mengenai bagaimana teori biaya transaksi dapat menjelaskan kemampuan brand sebagai jaminan kualitas produk.

Penetapan lokasi penelitian dilakukan dengan sengaja (purpossive sampling) di Kota Bengkulu. Sampel penelitian ini terdiri dari pemasar (pedagang besar, pengumpul, dan pengecer) dan konsumen ikan laut segar. Dalam penetapan sample penelitian ini nantinya akan digunakan metode sampling bertingkat (multistage sampling model), mulai dari pedagang besar di Tempat Pelelangan Ikan sampai dengan konsumen di pasar di tiap-tiap lokasi.

Penelitian ini menggunakan pendekatan deskriptif analisis dengan bantuan tabel dan grafik. Data hasil survei ditabulasikan dan dikelompokkan sesuai dengan kelompok atribut brand yang telah ditetapkan terdahulu untuk tiap-tiap lembaga pemasaran.

Data hasil survei tersebut berupa data ordinal yang bersifat kualitatif. Pertama, untuk mendapatkan deskriptif produk ikan laut segar Bengkulu dilakukan plotting kasus untuk memperbaiki variabel atau kelengkapannya. Kedua, guna menganalisis faktor-faktor yang berhubungan dengan brand equity pada produk ikan laut segar Bengkulu dilakukan analisis Pearson test untuk data yang telah dikelompokkan dan diskore berdasarkan kelompok atribut produknya. Setiap atribut produk (beneficial, characteristic, dan image) sebagai gambaran preferensi konsumen terhadap brand equity diuji tingkat signifikansi hubungannya terhadap brand equity (untuk atribut harga dan produk).

Pengujian statistik melalui Pearson test dipilih karena kajian ini mempergunakan dua sampel independen, menggunakan sampel kecil, dan memakai pengukuran (banyak percobaan yang ditempuh sebelum sampai pada patokan dianggap sebagai kekuatan brand) yang hanya dalam skala ordinal (Siegel, 1994).

Untuk menjawab tujuan penelitian yang kedua, yaitu menjelaskan respon konsumen atas produk ikan laut segar dengan harga sebagai konsekuensi brand dilakukan analisis tabulasi dengan menerapkan deskripsi statistik berupa nilai mean dan interval, sehingga akan diperoleh gambaran visual secara statistik respon konsumen terhadap brand (untuk atribut harga dan produk) yang diterapkan pada komoditas ikan laut segar di Kota Bengkulu. 


\section{HASIL DAN PEMBAHASAN}

\section{Profil Usaha Penjualan Ikan Laut Segar}

Kegiatan survey dilaksanakan pada dua lokasi pasar di wilayah Kota Bengkulu, yaitu Pasar Baru Koto dan Pasar Minggu, yang dipilih berdasarkan pertimbangan bahwa kedua pasar tersebut merupakan pasar terbesar di wilayah Kota Bengkulu. Khususnya untuk Pasar Baru Koto, pasar ini juga dikenal sebagai pasar ikan terbesar.

Ada 30 pedagang ikan segar dengan berbagai variasi produk di kedua pasar. Pedagang ikan segar menjual produk yang terdiri dari berbagai varian ikan segar berkelas berdasarkan musim, seperti ikan kakap, bawal, kerapu, jenihin, ekor kuning, baronang, gebur, dan marlin; varian ikan segar yang hampir selalu tersedia di pasar, seperti ikan tuna, mato besak, layur, sarden, tongkol, tenggiri, kapekape, dan ikan-ikan curah lainnya; varian hasil laut selain ikan, seperti cumicumi, udang (dengan berbagai kelas), kepiting, dan tiram.

Belum semua pedagang ikan segar Bengkulu menggunakan merek dagang, namun berdasarkan hasil pengamatan langsung dan wawancara dapat diketahui bahwa pedagang ikan segar di kedua lokasi penelitian telah memiliki kesadaran terhadap pentingnya brand image. Dari 30 pedagang ikan segar, terdapat 6 pedagang yang telah menggunakan merek dagang, yaitu 5 pedagang ikan tenggiri giling dan 1 pedagang ikan segar. Brand ditampilkan dalam bentuk spanduk yang ditempelkan pada bagian belakang lapak atau kios tempat penjualannya. Brand tersebut memuat informasi merek dagang, produk yang ditawarkan, pelayanan, dan alamat yang disertai nomer kontak.

Berdasarkan hasil pengamatan awal dan wawancara langsung kepada pedagang, maka objek penelitian ini akan diarahkan pada konsumen yang menjadi pelanggan, yaitu berbelanja lebih dari 3 kali, bagi pedagang ikan bermerek tersebut. Setelah diidentifikasi dan dianalisis, maka ditetapkan objek penelitian adalah pedagang ikan segar MAN RT yang berlokasi di Pasar Baru Koto. Pedagang ini adalah satu-satunya pedagang ikan segar yang menggunakan merek dagang, sedangkan pedagang lain yang menggunakan merek dagang secara spesifik hanya menjual daging ikan tenggiri giling, bukan ikan segar sebagaimana objek penelitian yang telah ditetapkan.

\section{Perilaku Konsumen dan Keputusan Pembelian Ikan Laut Segar}

Konsumen ikan laut segar membeli ikan secara terencana, baik mingguan maupun bulanan. Beberapa faktor penentu loyalitas konsumen terhadap pedagang ikan MAN RT adalah kualitas ikan yang baik dan kepastian harga produk. Adapun indikator loyalitas yang ditunjukkan oleh konsumen adalah jika ikan segar yang dicari konsumen tidak tersedia di tempat penjualan MAN RT, maka konsumen akan tetap membeli ikan di pedagang ikan MAN RT dengan jenis lain yang tersedia.

38 | Bonodikun, Putri Suci Asriani, Budiyanto, Preferensi Konsumen Ikan ... 
Beberapa faktor yang menjadi dasar pertimbangan konsumen dalam memutuskan tempat pembelian ikan laut segar adalah kualitas ikan laut segar yang paling baik dan produk ikan laut segar jenis apa pun (sesuai kebutuhan konsumen) tersedia di pedagang tersebut. Konsumen memutuskan pembelian didasarkan pada penilaian dari dalam diri sendiri, dengan merujuk pada kriteria produk (1) kualitas produk, (2) kontinyuitas ketersediaan produk di pasar, dan (3) variasi produk.

\section{Preferensi Konsumen Ikan Laut Segar terhadap Brand Equity}

Selera konsumen ikan laut segar terhadap kekuatan merek/pedagang langganan perlu diketahui agar pelaku bisnis jual beli ikan laut segar dapat mengevaluasi bagaimana selera konsumen terhadap kemanfaatan yang diperoleh (beneficial), karakteristik produk (characteristic), dan image produk ikan laut segar yang dijual. Secara lengkap, rata-rata hasil uji preferensi terhadap 3 karakteristik penilaian tersebut disajikan pada Tabel 1.

Tabel 1. Preferensi Konsumen terhadap Kekuatan Merek

\begin{tabular}{crrc}
\hline Tingkatan Preferensi & $\begin{array}{c}\text { Jumlah } \\
\text { (orang) }\end{array}$ & $\begin{array}{c}\text { Persentase } \\
\mathbf{( \% )}\end{array}$ & $\begin{array}{c}\text { Rata-rata } \\
\text { Skor }\end{array}$ \\
\hline Preferensi & & & \\
- Sangat Tinggi $(4,78-6,00)$ & 0 & 0 & $\mathbf{3 , 8 8}$ \\
- Tinggi $(3,52-4,77)$ & 19 & 95 & (Tinggi) \\
- Sedang $(2,26-3,51)$ & 1 & 5 & \\
- Rendah $(1,00-2,25)$ & 0 & 0 & \\
\hline \multicolumn{1}{c}{ Jumlah } & 20 & 100 &
\end{tabular}

Sumber: data primer diolah, 2013

Preferensi konsumen terhadap kekuatan merek yang digunakan oleh pedagang ikan segar di Kota Bengkulu, secara rata-rata masuk dalam kategori tinggi. Penilaian konsumen didasarkan pada kemanfaatan keberadaan merek (beneficial), ciri spesifik yang ada pada merek/pedagang pelanggan ikan laut segar (characteristic), dan gambaran yang melekat pada merek (image).

Faktor harga masih menjadi variabel penentu, konsumen ikan segar belum mendapatkan kepuasan dari segi harga. Ditinjau dari aspek beneficial, konsumen tidak mendapatkan harga yang lebih murah dibandingkan dengan tempat pembelian ikan lainnya yang tidak bermerek. Namun demikian hal ini tidak menjadi masalah, karena pada prinsipnya jika pada suatu produk sudah melekat brand maka bisa dipastikan ada peningkatan biaya transaksi, sehingga harga menjadi lebih mahal. Kondisi ini sudah sewajarnya, jaminan kualitas menjadi nilai lebih dari produk yang tersedia di tempat penjualan bermerek.

Harga yang berbeda tentunya harus diikuti dengan pelayanan yang berbeda pula, akan tetapi pada pedagang ikan laut segar bermerek di Kota 
Bengkulu belum menyadari bahwa kekuatan merek yang digunakannya merupakan jaminan kualitas produk. Selanjutnya berdasarkan pendapat konsumen terhadap berbagai pernyataan yang menggambarkan preferensi konsumen terhadap kekuatan merek (tersaji dalam daftar pertanyaan), dapat disajikan deskripsi preferensi konsumen tersebut, yaitu (a) Konsumen memperoleh kepastian mendapatkan produk; (b) Display produk teratur dan mudah memilih; (c) Variasi produk cukup beragam; dan (d) Waktu belanja menjadi lebih efisien.

\section{Faktor-faktor yang Berhubungan dengan Brand Equity Produk}

Kekuatan merek merupakan salah satu wahana strategi pemasaran yang harus dikembangkan dengan baik agar dapat meningkatkan penjualan. Variabel kemanfaatan keberadaan merek (beneficial), ciri spesifik yang ada pada merek/pedagang pelanggan ikan laut segar (characteristic), dan gambaran yang melekat pada merek (image) diduga berhubungan dengan kekuatan merek (brand equity). Bedasarkan hasil analisis uji Pearson terhadap variabel dependent (kekuatan merek_Y) dan variabel independent (beneficial_X1, characteristic_X3, dan image_X4), dapat diketahui bahwa aspek kemanfaatan keberadaan merek dan image secara signifikan berhubungan positif dengan tingkat keeratan hubungan kurang erat terhadap brand equity. Hasil analisis lengkapnya disajikan pada Tabel 2.

Tabel 2. Hasil Uji Hubungan Beneficial (X1), Characteristic (X3), dan Image (X4) terhadap Brand Equity (Y)

\begin{tabular}{|c|c|c|c|}
\hline $\begin{array}{c}\text { Variabel } \\
\text { Independent }\end{array}$ & $\begin{array}{c}\text { Pearson } \\
\text { Koefisien }\end{array}$ & $\begin{array}{c}\text { Sig. } \\
\text { (1-tailed) }\end{array}$ & Ket. \\
\hline Beneficial (X1) & $0,389^{*}$ & 0,045 & Berhubungan kurang erat \\
\hline Characteristic (X3) & 0,256 & 0,138 & Tidal \\
\hline Image $(X 4)$ & $0,472^{*}$ & 0,018 & Berhubungan kurang erat \\
\hline \multicolumn{4}{|c|}{$\begin{array}{l}\text { *. Correlation is significant at the } 0.05 \text { level (1-tailed); Sig. (1-tailed) }<0,05 \\
\text { Sumber: data primer diolah, } 2013 \\
\text { Variabel kemanfaatan merek (beneficial) yang menggambarkan kepuasan } \\
\text { konsumen atas kepastian, kemudahan, keragaman, jaminan kualitas, dan } \\
\text { jaminan harga dalam mendapatkan produk ikan laut segar secara signifikan } \\
\text { berhubungan dengan kekuatan merek yang digunakan oleh pedagang. } \\
\text { Demikian halnya untuk variabel gambaran yang melekat pada merek (image) } \\
\text { yang terdiri dari jaminan harga terhadap kualitas, jaminan keamanan produk, } \\
\text { dan jaminan kemudahan akses juga menunjukkan hubungan yang signifikan } \\
\text { terhadap brand equity ikan laut segar. Namun untuk variabel characteristic tidak } \\
\text { menunjukkan hubungan yang signifikan terhadap brand equity. }\end{array}$} \\
\hline
\end{tabular}

40 | Bonodikun, Putri Suci Asriani, Budiyanto, Preferensi Konsumen Ikan ... 
Dari hasil analisis ini dapat disampaikan bahwa beneficial dan image penggunaan merek pada pedagang ikan segar menunjukkan hubungan yang positif terhadap (brand equity) yang melekat pada produk. Konsumen, walaupun belum menyadari sepenuhnya, dapat menikmati keberadaan merek sebagai jaminan kualitas produk ikan laut segar.

\section{Respon Konsumen terhadap Harga dan Produk sebagai Konsekuensi Brand}

Respon konsumen terhadap harga dan produk dijelaskan sebagai perilaku konsumen. Respon itu sendiri tergambar dari perilaku konsumen dalam memposisikan pedagang ikan bermerek/langganan. Sebaik apapun merek dirancang, namun baik tidaknya respon konsumen harus ditunjukkan dengan perilaku pembelian oleh konsumen sebagai ukuran keberhasilannya. Ukuran tinggi rendahnya respon konsumen terhadap harga (yang terdiri dari kesesuaian harga dengan kualitas dan pelayanan) dan produk (yang terdiri dari jaminan kualitas, keragaman, dan ketersediaan ikan laut segar) didokumentasikan sebagai pengetahuan baru yang dijadikan dasar konsumen dalam berperilaku dalam melakukan aktivitas pembelian ikan laut segar. Respon konsumen terhadap harga dan produk disajikan pada Tabel 3.

Berdasarkan hasil analisis diketahui bahwa respon konsumen terhadap keberadaan merek yang digunakan oleh pedagang ikan laut segar sebagai jaminan kualitas adalah sangat baik. Konsumen merasa puas dengan pelayanan yang diberikan oleh pedagang ikan bermerek/langganan dengan menunjukkan perilaku sebagai berikut: (a) Konsumen merasa puas dengan pelayanan penjualan yang diberikan oleh pedagang ikan bermerek/langganan; (b) Konsumen loyal dengan pedagang ikan bermerek/langganan; dan (c) Konsumen memutuskan untuk menjadi pelanggan pedagang ikan bermerek/langganan.

Tabel 3. Respon Konsumen terhadap Harga dan Produk sebagai Konsekuensi Brand

\begin{tabular}{|c|c|c|c|}
\hline Tingkatan Respon & $\begin{array}{l}\text { Jumlah } \\
\text { (orang) }\end{array}$ & $\begin{array}{c}\text { Persentase } \\
(\%)\end{array}$ & $\begin{array}{c}\text { Rata-rata } \\
\text { (Score) }\end{array}$ \\
\hline \multicolumn{4}{|l|}{ Respon Konsumen } \\
\hline - Sangat Baik $(4,78-6,00)$ & 13 & 65 & 5,015 \\
\hline - Baik $(3,52-4,77)$ & 7 & 35 & (Sangat Baik) \\
\hline - Sedang $(2,26-3,51)$ & 0 & 0 & \\
\hline - Rendah $(1,00-2,25)$ & 0 & 0 & \\
\hline Jumlah & 20 & 100 & \\
\hline
\end{tabular}

Sumber: data primer diolah, 2013 


\section{SIMPULAN DAN SARAN}

\section{Simpulan}

Tingkat preferensi konsumen terhadap brand yang digunakan oleh pedagang ikan segar di Kota Bengkulu adalah tinggi. Penilaian konsumen didasarkan pada kemanfaatan keberadaan merek (beneficial), ciri spesifik yang ada pada merek/pedagang pelanggan ikan laut segar (characteristic), dan gambaran yang melekat pada merek (image). Variabel beneficial dan image penggunaan merek pada pedagang ikan segar di Kota Bengkulu memiliki hubungan yang positif terhadap brand equity yang melekat pada produk. Respon konsumen terhadap keberadaan merek yang digunakan oleh pedagang ikan laut segar di Kota Bengkulu sebagai jaminan kualitas adalah sangat baik.

\section{Saran}

Implikasi dari hasil penelitian ini adalah disarankan untuk mengembangkan penggunaan papan merek pada pedagang ikan segar di Kota Bengkulu sebagai jaminan kualitas, karena beberapa keunggulan produk akan dicapai, yaitu (1) kualitas produk terjamin baik; (2) terdapat jaminan kepastian harga dan harga yang terbentuk bersaing; (3) terdapat kepastian jaminan keamanan produk; dan (4) konsumen mudah memperoleh produk dengan adanya kemudahan akses berbelanja.

Upaya peningkatan kualitas pemasaran produk ikan laut segar melalui penggunaan brand memerlukan beberapa saran perbaikan untuk beberapa hal berikut: (1) Jaminan harga yang murah; (2) posisi tempat penjualan yang strategis; (3) papan merek mampu menyajikan informasi produk yang akan dibeli; (4) posisi tempat penjualan strategis, sehingga dapat langsung terlihat (fokus) pada saat konsumen memasuki pasar; (5) papan merek dilengkapi dengan nomer register, sehingga dapat dijadikan wahana promosi dengan jaminan kualitas yang pasti; (6) berbagai wahana promosi digunakan, termasuk melalui iklan; dan (7) membuat design merek yang menarik minat pembeli.

\section{DAFTAR PUSTAKA}

Anderson, P. 1982. Commercial Fisheries Under Price Uncertainty. Journal of Environmental Economics and Management, 9 (1):11-28.

Barcala, Marta Fernăndez. dan Diaz, Manuel Gonzăles. 2006. Brand equity in the European fruit and vegetable sector: A transaction cost approach. International Journal of Research in Marketing 23: 31-44.

Huseini, Martani. 2007. Masalah dan Kebijakan Peningkatan Produk Perikanan untuk Pemenuhan Gizi Masyarakat: Makalah Seminar Nasional Hari Pangan

42 | Bonodikun, Putri Suci Asriani, Budiyanto, Preferensi Konsumen Ikan ... 
Sedunia. Dirjen Pengolahan dan Pemasaran Hasil Perikanan Departemen Kelautan dan Perikanan RI. Jakarta.

Koswara, Sutrisno. 2006. Labelisasi dan Teknik GMO. Http//www.Ebookpangan.com.

Peter, J. Paul; Olson, Jerry C. 2000. Consumer Behavior: Perilaku Konsumen dan Strategi Pemasaran. Penerbit Erlangga. Jakarta.

Siegel, Sidney. 1994. Statistik Non Parametrik. Penerbit PT Gramedia Pustaka Utama. Jakarta. 